\title{
THE CHOICE BETWEEN MORAL ENHANCEMENT AND ULTIMATE HARM
}

\begin{abstract}
Ultimate harm" can be defined as the result of a catastrophic event or series of events that permanently destroy sentient life on Earth or make its conditions so unbearable that it cannot be considered worthy of living anymore. In order for us to seriously reduce the likelihood of ultimate harm, eudaimonic agents have to become dominant in humanity. Their dominance will be established if humanity embarks on the path of moral enhancement, including moral bio-enhancement. It will be argued that moral and cognitive enhancement are to be combined in such a way that all cognitive enhancement has moral enhancement as its objective. It will also be demonstrated why the domination of the eudaimonic type can best be attained in a liberal singleton, and why such a singleton is an increasingly realistic perspective in the time to come. Ultimate harm, however, will also continue to be a likely scenario.
\end{abstract}

\section{1.}

Some technological advances are augmenting the self-destructive opportunities of humanity. They include nuclear weapons, environmental hazards, but also new bio-technologies. Persson and Savulescu argue that these advances are not being accompanied by a corresponding moral advance that would be a reliable safeguard for humanity to prevent its self-annihilation or a somewhat milder form of ultimate harm; ultimate harm being defined as something that can permanently annihilate sentient life, or damage its conditions so drastically that, in general, life will not be worth living anymore (see Persson and Savulescu 2011c).

I will argue that for humanity to diminish the probability of ultimate harm, the eudaimonic type of agents has to become dominant. This type I understand here in a Stoic sense. Aristotle considers the exercise of virtue to be the most important ingredient in eudaimonia but acknowledges, in addition to that, the importance of external goods (such as wealth). For Stoics, on the other hand, virtue is necessary and sufficient for eudaimonia. Wealth and other external goods are thus dispensable. Because eudaimonia consists of a true comprehension and exercise of virtue, it enhances us morally. If morally enhanced, humanity will be less likely to obliterate itself.

Non-eudaimonic agents dominate the contemporary world. In line with Bostrom (2009), I understand them as "fitness-maximizing competitors". These agents can be individuals, groups or institutions. On a global level: non- 
eudaimonic agents will continue to dominate the contemporary world as long as multiple states compete for scarce resources. It is hard to imagine that a serious moral advance of humanity is realistic if states that compete with each other have the authority to oversee technological advances and impose moral limitations on them. Hence, a singleton appears to be a prerequisite of moral enhancement. A singleton is understood here as a global agency that is endowed with a single decision-making power at the supreme level of its authority. This power is in full control over its domains, permanently preventing both internal and external threats to its ultimate global authority ${ }^{1}$.

A case in point is point is artificial intelligence (AI). Super- human intelligence ought to be accompanied by super-human morality, because a cognitively uploaded human is a danger to society if her superb intelligence is not monitored by a superb moral sense. In that case, she will use her intelligence to overpower her competitors, while her actions will remain without a respectable moral value. Hence, in order to prevent this from happening, the super-intelligent human ought to belong to the eudaimonic type. For a responsible development of AI, such type ought to dominate the power structures in the world. This domination can best be secured in a singleton ${ }^{2}$.

Opponents of the idea that a singleton is a suitable means leading toward the social domination of the eudaimonic type in humankind have the possibility to forward three essential reasons for their skepticism:

1) Some types of moral and cognitive enhancement (ME and CE) are a matter of philosophical debate, but do not exist in "real life" (examples: artificial intelligence or neuro-surgical interventions that might enhance us morally); hence, moral enhancement and the social domination of the eudaimonic type are not likely at present.

2) Some moral enhancements might only make us understand morality better, but will not necessarily make us act in nicer ways; hence, we can only cognitively enhance ourselves, whereas full moral enhancement (= comprehension of morality + moral behavior) is not plausible; thus, the social domination of the eudaimonic type is generally implausible.

3) A singleton might not be realistic in the near or mid-term future; hence, it is not possible to create the necessary conditions for a social domination of eudaimonic agents.

All three reasons bring into question the likelihood of humankind becoming predominantly eudaimonic, either immediately (reason 1), in general (reason 2 ) or in the relatively near future (reason 3 ). The first reason, however, is not

1 For a comparable concept of the singleton, see Bostrom (2006).

2 To make sure that the singleton will secure a domination of eudaimonic agents, it can be supportive of:

- existing eudaimones;

- moral enhancement of the world population by education, medication or neuro-surgical interventions that might stimulate trust, empathy and other morally desirable traits;

- the development of super-human and super-moral AI. 
relevant here: it addresses the current state of affairs, a state of affairs that is being overcome incessantly. Moreover, some cognitive and moral enhancements are taking place already by non-traditional means (e.g., medication is becoming an ever more popular vehicle for enhancement), while further advances of that type are a credible perspective in the relatively near future. Hence, in what follows I will discuss and refute 2) and 3) only.

The first conclusion will be that a specific combination of cognitive and moral enhancement will truly enhance not only our comprehension of morality, but also the moral value of our deeds. Hence, it will make us more eudaimonic. The second conclusion will be that eudaimonia can best be achieved in a liberal singleton, while such an eudaimonic singleton is becoming an increasingly realistic option. The third conclusion will be that the self-obliteration of humanity (or another form of ultimate harm) is also remaining a possible scenario.

In this chapter I will elaborate on the concept of "integrated neuro-enhancement". This type of enhancement has not only the potential of making us understand morality better, but also of making us act more in line with this understanding.

Persson and Savulescu (2011a) address the issue of moral enhancement in a vigorous manner. The authors diagnose a misfit between a limited human moral nature and globalized, highly sophisticated technology. As the progress of scientific technology has been steadily increasing, the human capacity to cause harm has reached the stage at which life on Earth might be annihilated. The root of the problem is that human moral psychology has been adapted to life in small, cohesive societies with primeval technology, while it is unprepared for the moral challenges of a technologically advanced global society. The development of advanced scientific technology appears to have resulted in the need for a radical change of human moral dispositions. The misfit between a limited human moral nature and a technologically sophisticated global society ought to be ameliorated by ME, in order to achieve restraint, promote cooperation, develop respect for equality, as well as other values that are now necessary for the survival of humanity. And it is scientific progress, the cause of this misfit, that might be employed to address it - by offering means leading to the enhancement of our capacity for moral behavior. But that is precisely where the caveat ("the bootstrapping problem") is: human beings, i.e. those who need to be morally enhanced, are the ones who have to make a morally wise use of the techniques of moral enhancement (Ibid., 498).

I have argued elsewhere that the only morally permissible solution to the "bootstrapping problem" appears to be to promote exclusively those types of CE that lead to ME: human beings, i.e. those who need to be morally enhanced, will make a morally wise use of the techniques of cognitive enhancement by ensuring that all cognitive enhancement serves a moral purpose. Serving a moral 
purpose it contributes to our moral enhancement ${ }^{3}$. Hence, we need to approach cognitive and moral enhancement as a single project. Our objective ought to be cognitive plus moral enhancement, $(\mathrm{C}+\mathrm{M}) \mathrm{E}$. I called it "integrated neuroenhancement" (Rakić 2012).

I have argued that integrated neuro-enhancement is to be delineated in the following manner from the position of Persson and Savluescu (I will call their outlook "position 1", while my standpoint I will call "position 2"):

1) The argument that $\mathrm{ME}$ ought to "accompany" $\mathrm{CE}$ implies that the latter should be avoided until we are sufficiently morally enhanced (Persson and Savulescu 2008: 166, 174). I have argued that to "to accompany" is to be understood here as "to precede" (Rakić 2012, 118-119). In other words, position 1 is in favor of CE after ME. Position 2, on the other hand, is against the idea of postponing CE in anticipation of ME. Nevertheless, it poses a significant limitation to $\mathrm{CE}$, claiming its acceptability only if leading to ME.

2) If $\mathrm{ME}$ is to become compulsory, as is claimed by some proponents of position 1 (including Persson and Savulescu), our freedom will obviously be restricted. Conversely, position 2 is not in favor of making ME obligatory, maintaining that only voluntary $(\mathrm{C}+\mathrm{M}) \mathrm{E}$ will leave our freedom intact ${ }^{4}$.

3) Position 1 fails to give a solution to the problem of how competent decisions on $\mathrm{ME}$ can be taken by ordinary humans, i.e. by those who have to be morally enhanced. This failure is a consequence of position 1 regarding $\mathrm{ME}$ too much in isolation from $\mathrm{CE}$. In fact, by treating ME as something that ought to take place before $\mathrm{CE}$, it is not supportive of either one of them. Position 2, on the other hand, considers CE and ME as highly related processes (Rakić 2012, 121).

How can integrated neuro-enhancement ameliorate the concerns Persson and Savulescu raise regarding the danger of ultimate harm? According to Persson and Savulescu, the danger of ultimate harm has become reality as a consequence of technological developments in the previous decades taking place at a faster pace than our moral development. We fear that life can be extinguished on our planet and are willing to do whatever we can to eliminate that possibility, even if the chance of it becoming reality is very slight. An increase in the probability of ultimate harm from 0.05 to 0.1 might not noticeably affect the intensity of our fear, whereas an increase in it from 0 to 0.05 could strike us with horror. Hence, we have to make sure that $\mathrm{CE}$ is accompanied (=preceded) by ME (according to Persson and Savulescu).

3 Moral enhancement I understand here in a broad sense. Most importantly, it includes those types of cognitive enhancement that serve a moral purpose. This understanding is warranted, because an increase in number of acts with a moral purpose enhances us morally. Acts with a moral purpose, I assume, include those that are directed to achieving the well-being of others, but also of oneself - provided that these acts do not harm others.

4 For my elaboration on voluntary moral enhancement, see Rakić (2013a). For a reply to my argument, see Persson and Savulescu (2013). 
On the other hand, reader, can we ever fully eliminate the possibility of our self-annihilation? Nuclear, bio-technological and other weapons of mass destruction may end up in the hands of one or more deranged individuals who can inflict ultimate harm with them. Our security will not be guaranteed if we postpone CE. Cognitive bio-enhancement should not wait until humanity acquires appropriate moral capacities to deal with the potentially destructive technological means that are at its disposal. A small number of psychopaths are sufficient to cause ultimate harm. We have to learn to live with the idea that this harm will remain a possibility. The probability of the annihilation of humankind will never be 0 . Hence, we can only try to keep its likelihood at a minimum. Cognitive bio-enhancement is a fiddly path - as are many other contemporary technological advances. But if we make sure that it leads to ME, we can reasonably expect that we have done what is in our power to keep the probability of ultimate harm as low as possible.

In order to shed some more light on the concept of $(\mathrm{C}+\mathrm{M}) \mathrm{E}$, let us look now at a number of examples. General cognitive capacity is positively correlated with various morally desirable outcomes. It diminishes the risk of a variety of economic and social calamities, including bad health, accidents (even being the victim of homicide), while reducing overall mortality and improving educational outcomes (Bostrom 2009). Jones contends that in prisoner's-dilemma type experiments individuals with higher cognitive potentials cooperate more often and have a stronger future orientation - something that appears to promote economic success and decrease the likelihood of morally undesirable outcomes (Jones 2008).

Robin Hanson addresses one attribute that can be associated with both our cognitive and moral capacities: truth-orientation. Enhanced truthfulness can result in a reduction of self-deception and bias - vices that are especially dangerous in a modern world with a variety of potentially hazarduous technologies (Hanson 2009). Since these vices have both a cognitive and moral side, $\mathrm{CE}$ that strengthens our truth-orientation has a moral purpose. It is $\mathrm{CE}$ that leads to ME.

There are a variety of laws and regulations with both a cognitive and a moral side. Bostrom gives the following examples of safeguards of cognition: regulation of lead in paints and water; requirements of boxing, bicycle, and motorcycle helmets; bans on alcohol for minors; mandatory education; folic acid fortification of cereals; legal sanctions against mothers taking drugs during pregnancy (Bostrom 2009). These laws and regulations do not only safeguard or promote cognition, but in addition to that, they have a moral purpose.

Bostrom also discusses recent studies indicating that children's IQ can be boosted up by increasing maternal docosahexaenoic acid (DHA) intake during pregnancy. This increase can be accomplished by supplementing infant formula with DHA. Furthermore, cognitive function can be enhanced by the treatment of hundreds of millions of people worldwide suffering from iodine deficiency. Iodine deficient populations average between 12.5 and 13.5 IQ points less than normal populations (Bostrom 2009). Hence, by supplementing infant formula with DHA and by iodizing salt in areas that are worst affected by iodine 
deficiency (sub-Saharan Africa, South Asia, but also Central and Eastern Europe and the CIS), we cognitively enhance populations with a moral purpose.

Unlike the mentioned examples of $(\mathrm{C}+\mathrm{M}) \mathrm{E}$, cognitive enhancement without a moral purpose can hardly be considered as morally justified. At the very least, it has a morally ambiguous status. The use of methylphenidate with the aim of providing oneself with a comparative advantage over classmates would be an example $^{5}$. In this context, it is useful to compare medicine in general with sports medicine. Tjorbjorn Tannsjo believes that in medicine in general we are to accept both enhancement and what he calls "positive measures" (the improvement of functioning of a human organism within the range of natural variation). In sports medicine, on the other hand, both enhancement and positive measures are considered as morally dubious, because in elite sports we search for the limits of human capacities, endorsing a very specific notion of justice according to which we think highly of individuals who excel for having been endowed with something valuable in the natural genetic lottery. Let it be noted that Tannsjo rejects this notion of justice (Tannsjo 2009). In the perspective that promotes integrated neuro-enhancement $(\mathrm{C}+\mathrm{M}) \mathrm{E}$, enhancement in general and enhancement in sports medicine are both difficult to accept if they do not serve a moral purpose.

The "recreative" use of anti-depressants and tranquilizers (in order to improve our normal mood) can possibly serve the purpose of making us feel better. Such a purpose might be considered to be morally justified, according to the criterion of "acts with a moral purpose" from footnote 3 . The recreative use of the mentioned drugs would then be an example of $(\mathrm{C}+\mathrm{M}) \mathrm{E}$ : it can possibly help us improve our well-being without causing harm to others. In that sense, it differs from the use of methylphenidate with the purpose of achieving a comparative advantage over competitors.

$(\mathrm{C}+\mathrm{M}) \mathrm{E}$, as demonstrated in the previous paragraphs, makes us understand morality better. But it also has a favorable impact on the moral enhancement of our behavior. It helps us acting in nicer ways. To some extent it bridges the gap between what we do and what we believe we ought to do. In other words, $(\mathrm{C}+\mathrm{M})$ $\mathrm{E}$ not only makes us understand morality better, but can also make us act in nicer ways. Hence, $(\mathrm{C}+\mathrm{M}) \mathrm{E}$ casts doubt on the justifiability of the second reason for skepticism about the eudaimonic singleton (Chapter 1).

The third reason for cautiousness: a singleton might not be realistic in the near or mid-term future. Since $(\mathrm{C}+\mathrm{M}) \mathrm{E}$ is a serious response to the second reason, the question is whether it might also be response to reason 3. In other words, is a singleton an appropriate format for achieving $(C+M) E$ ?

In this chapter I will employ Kant's notion of the "ethical commonwealth" and his duty-based assumptions regarding the purpose of history, the evidence that the number of liberal states has been on the increase in the previous $200+$

5 On the other hand, there is nothing morally doubtful in using methylphenidate for improving our motivation or boosting our self-confidence without the purpose of achieving an advantage over others in a competitive setting. 
years (specifically Michael Doyle's findings), as well as my own contentions from Rakić (2010b). I will do that in order to boost the idea that humanity is gradually becoming more moral. I will show that $(\mathrm{C}+\mathrm{M}) \mathrm{E}$ is therefore also something that is becoming increasingly realistic, that it will aid humanity's historical trend towards more freedom and justice, and that a liberal singleton is the preferred institutional arrangement for $(\mathrm{C}+\mathrm{M}) \mathrm{E}$.

Nick Bostrom offers the following options for a singleton. A singleton could be a democratic world government, a benevolent and overwhelmingly powerful super-intelligent machine, a world dictatorship, a stable alliance of leading powers, or even something as abstract as a generally diffused moral code that includes provisions for ensuring its own stability and enforcement (Bostrom 2009).

The most desirable option is a liberal singleton. A world dictatorship, even if "enlightened", is neither a realistic nor a desirable option. Most of humanity can hardly be expected to be interested in being enlightened by a government that has been imposed on it. The "developed world" has already passed the stage of history that was marked by absolutist governance. And even if a return to absolutist governance were realistic, it is not desirable to embark on that path if a singleton can be achieved without our freedom being encroached upon.

A singleton in the form of a stable alliance of leading powers, a generally diffused moral code or even a super-intelligent machine would, even if possible, have to preserve individual freedoms of its subjects. Otherwise, the world would (re)turn to authoritarian governance, that is to a historical stage (much of) humanity has already left behind. Moreover, in an authoritarian singleton we would not be able to opt voluntarily for eudaimonic lifestyles. This means that eudaimonia itself would be compromised. Reason: if we cannot exercise virtue voluntarily, we cannot be regarded as virtuous. All in all, a liberal singleton is to be preferred to an authoritarian one.

Is liberal democratic global governance with a moral purpose a realistic option? In order to answer this question, let us turn to a philosopher who had something to say about this issue more than 200 years ago: to Kant, specifically to his idea of the "ethical commonwealth". In Religion Within the Boundaries of Mere Reason (RBMR) Kant makes clear that the ethical commonwealth is more than one particular church. It is the one, true, invisible Church, but also "a universal republic based on the laws of virtue" (emphasis added) ${ }^{6}$. Hence, the meaning of the ethical commonwealth extends to a world state.

Kant's apparent incoherence in advocating in Toward Perpetual Peace (TPP) a federation of states, instead of a world state, indicates that his aims there were quite different from those in $R B M R$. In $R B M R$ he endeavored to give an account of the final condition which humanity ought to attain (and is gradually attaining). In $T P P$ he was concerned with an intermediate phase, the stage humanity ought to aspire in the more immediate future. At that stage, a world state is still not achievable - because of the imperfections of humanity. After humans have made sufficient moral progress, a universal state and Church will become possible. Before that, a federation of states will have to $\mathrm{do}^{7}$.

6 For the concept of the ethical commonwealth, consult Kant (1793).

7 For a broader elaboration of this argument, see Rakić (2013b). 
In interpreting Kant's view on international relations, one therefore needs to have a clear picture of the stage of the future Kant is referring to: the far future (i.e., the approximation of the final stage of human development) or the more immediate future. $R B M R$ deals more with the former, TPP with the latter. The singleton is something Kant certainly would have considered as a phenomenon from the farther future (although not necessarily as the "final stage of human development").

Since it has been posited here that a singleton should be a liberal global government that is to ensure the moral aptness of humankind, it makes sense to understand its meaning in line with Kant's conception of the ethical commonwealth: of a state of affairs that can be described as global justice. But what is justice after all and how far is humanity from achieving world justice? In Rakić (2010a) I have argued along the following lines (the subsequent paragraphs are aimed at establishing a cogent link in my overall argumentation between this chapter and the previous one).

Justice is a state of affairs we believe ought to exist as a common standard. The reason why it ought to exist is not always rationally comprehensible. Why we ought to help those who are in need of help, or why you, reader, will feel bad if grabbing the only seat in a bus just in front of a disabled person (in spite of the fact that you might get away with it unpunished in any form) is not something we can explain in terms of our rational interest. It is a moral sense that tells us that we are abandoning a "code" according to which things ought to happen if we do not act in a way we feel is morally proper. This code is not a written code or any other socially determined law. Its essential element is the concept of the "one thinking in terms of all", which primarily includes the abandonment of mere self-interest. It is a code that is outside the political realm and is therefore different from Rousseau's concept of the general will (which Rousseau also defines by using the formulation of "the one thinking in terms of all"). Let us call it the moral code.

Is this code subjective or objective? It is subjective in the sense that we act justly or not on the basis of our personal morality, i.e. our positioning towards the moral code. Our moral preferences are not defined in a set of rules specifying the content of the moral code. Moreover, this code is not accepted in a number of specific societies, but contains something that comes close to general validity in humanity. It is thus not particularistic, but universal. Being different from Rousseau's general will (which is political, i.e. particularistic as long as there is no world state), I term it the normative will of humanity, And that will is precisely what justice is. It is a stable ethical and universal will, not a changing political and particularistic one.

In that sense, the moral code, justice, as well as the normative will of humanity have an objective value. Objectivity in the moral realm is secured when a moral act approaches consensus in humanity. The moral code or justice cannot achieve the sort of objectivity characterizing natural sciences, but objectivity can indeed be attained in the moral realm if moral actions are judged by their acceptance in the largest possible community, i.e. in humanity.

The question now is how we can act in a just manner. A prerequisite for acting intentionally in a just manner is to be free. Without being free, one cannot 
act in a just manner because she wills so, but only because she is forced to. A truly just act, on the other hand, is one that is performed on the basis of our free will. The issue of justice is thus to a significant degree an issue of freedom. In fact, justice is founded in our free will.

If we can prove that our historical development is marked by an expansion of freedom, the implication is that humanity's's opportunity of intentionally achieving global justice is also expanding. And if we define justice as the normative will of humanity, justice has plainly cosmopolitan underpinnings. Not only that justice that transcends national boundaries is superior to particularistic concepts of justice, but it has the best perspective of being realized in a liberal singleton.

Let us turn now to a testimony in favor of the thesis that the number of liberal states is on the increase in modern history: Michael Doyle's article "Kant, Liberal Legacies, and Foreign Affairs (parts I ands II)" (Doyle 1983). Afterwards I will substantiate the link between freedom and justice. Doyle provides in his article cogent empirical evidence for the continuous increase in number of liberal states in the last two hundred years. His findings are the following: in the $18^{\text {th }}$ century three liberal regimes, between 1800 and 1850 eight, between 1850 and 1900 thirteen, between 1900 and 1945 twenty nine, and after 1945 forty nine ${ }^{8}$.

If Doyle's findings for states are applied to individuals, i.e. if an increase in number of liberal states implies an increase in number of free individuals, we might conclude that we inhabit a world that is becoming increasingly free and hence has an augmented potential of being just ${ }^{9}$. Consequently, indirect support is furnished for the idea that justice is coming nearer. After forcefully supporting the thesis that the number of liberal states is on the increase, Doyle also presents empirical evidence for the hypothesis that liberal states do not wage wars against each other. Hence, support is also provided for the idea that we inhabit a world that is gradually becoming more peaceful.

There are, however, also non-historical arguments that indicate that justice might be coming nearer. I will present two of them, one from the domain of political philosophy, the other a purely logical one $e^{10}$ :

(1) Ever larger portions of humanity becoming free, means that not only the concept of freedom will be enacted into laws, but also the concept of equality (slaves or serfs were obviously not equal to free citizens, whereas all citizens in liberal states are assumed to be equal). Since freedom is the pre-condition for intentional just actions, and since the concept of justice as the "one thinking in terms of all" is inseparable from the postulate of equality of all individuals (Rakić 2010a, 21-22), it is justice that is being increasingly present in the legal systems of our world. Consequently, ever larger portions of humanity will acquire the

8 It is relevant to emphasize that Doyle's article was published in 1983, i.e. before the breakdown of state-socialism in Central and Eastern Europe. As we know, this breakdown was followed by a further increase in number of liberal states.

9 For my substantiation of the idea that our historical development goes in the direction of an expansion of freedom and justice, see Rakić (2010a, 17-23, 25-28, 67-71 and 93-101).

10 For these two, as well as for other arguments in favor of the thesis that history is approaching justice, see again Rakić (2010a, 21-22). 
"habit of justice"11, which will have its impact on education, media and other components of communication conducive to a just, liberal (political) culture. This argument favors the conception of history as the development of justice, and not only as the development of freedom.

(2) The logical argument is the following. Since we do not act as we know we ought to act, history will by necessity reach a stage at which this discrepancy will disappear. It is unimaginable, namely, that human beings will never reach a point at which they will act as they believe they ought to. Thus, if we presuppose that history will last sufficiently long, even if that implies the assumption of eternity, human beings will at one point in time act in full agreement with how they believe they ought to act. ${ }^{12}$. That will be a stage at which we are going to act in accordance with justice on the basis of our free will. As a matter of fact, we will use our freedom with justice as its purpose.

Let us return to Kant. We have seen that the ethical commonwealth is a perfectly just community that consists of morally advanced humans. Kant asserts that we are gradually coming closer to the historical stage marked by this concept. It is a concept that Kant uses to describe what might be interpreted as the "purpose of history". Kant's understanding of history is fundamentally a moral one, because the alternative to the view of history serving a purpose would be to accept the possibility of humans regressing to barbarism. Ultimately, the affirmation of progress is motivated not by empirical or theoretical but by moral consideration. Consequently, a society marked by the ethical commonwealth and by self-perpetuating peace as the final stage of humanity's historical progress is also morally motivated.

But what does this moral motivation entail? For Kant, it is duty. We are morally obliged to assume the arrival of justice, i.e. the establishment of the ethical commonwealth and perpetual peace. It is useful to link Kant's concepts of the ethical commonwealth and perpetual peace to his postulations on the immortality of the soul and the existence of God. Kant, namely, derives the postulate on the immortality of the soul from his understanding that the highest good (morality) can only be accomplished by assuming an endless development of the human capacity for the good. The highest good can only be attained in eternity. Because of that, it is our moral duty to assume the immortality of the soul. Concerning the existence of God, Kant provides us with a related argument: the achievement of the highest good is not possible without God, and hence we are morally obliged to postulate God's existence ${ }^{13}$. All in all, it is duty that makes us assume the development of the world in the direction of justice (marked by the ethical commonwealth and perpetual peace), as it is our duty to presuppose the immortality of the soul and the existence of God.

11 For an explanation of the concept of the "habit of justice" see Rakić (2010a, 64-65).

12 A development in the opposite direction is unrealistic, because the history of the expansion of freedom and justice is accompanied by a corresponding history of human thought. This history cannot be reversed. The stage that the ideas of freedom and justice have reached cannot be passed in reverse.

13 For Kant's arguments in favor of the immortality of the soul and the existence of God, see Kant (1788). 
In light of the lines of reasoning that have been presented here in favor of the thesis that history is approaching justice (Doyle's indirect argument based on the increase in number of liberal states in modern history, my own contentions and Kant's duty-based concepts), it is to be concluded that robust support can be furnished for this optimistic idea. Deriving my argumentation from Kant's concepts about the ethical commonwealth and the purpose of history, I have also shown that justice as the normative will of humanity is to be attained in a world state that is not authoritarian: in a liberal singleton. I have also argued that humanity is progressively approaching justice. Consequently, humanity appears to be advancing toward a liberal and eudaimonic singleton.

But the danger of ultimate harm is also real. In order to avoid it, we have to make sure that our enhancements proceed on the basis of the $(\mathrm{C}+\mathrm{M}) \mathrm{E}$ formula. The application of this formula is thus also essential when our advance toward a liberal singleton is concerned - if ultimate harm is to be avoided.

New technologies (specifically, integrated neuro-enhancement) will accelerate our progress toward justice, because they will advance a moral sense in us that will help our survival and well-being in the face of the dangers we face. In other words, although it is difficult to predict if and when a singleton will be achieved, the likelihood of it being attained in the relatively near future is increasing. Hence, humanity becoming progressively more moral and new technologies speeding up this trend cast doubt on the justifiability of the third reason for skepticism about the eudaimonic singleton (Chapter 1).

Two essential implications of Chapter 3 are:

- the moral advance of humanity that is aided by the development of new technologies increases the likelihood of a liberal and eudaimonic singleton becoming reality in the relatively near future;

- a singleton is an appropriate format for attaining $(\mathrm{C}+\mathrm{M}) \mathrm{E}$.

4.

It has been argued that $(\mathrm{C}+\mathrm{M}) \mathrm{E}$ might ensure that bio-enhancements will not only make us understand morality better, but will also lead us to act in nicer ways. In addition to that, the moral advance of humanity is bringing us closer to a singleton. It has been contended that Kant's ethical commonwealth in the form of a just world state ("a universal republic based on the laws of virtue") is an option that is becoming increasingly realistic. A liberal singleton governed by super-smart and super-moral intelligence (artificial or not) may not lie too far in the future.

In sum:

- The domination of eudaimonic agents in humanity is to be attained by us following the path of $(\mathrm{C}+\mathrm{M}) \mathrm{E}$.

- $\quad(\mathrm{C}+\mathrm{M}) \mathrm{E}$ can best be achieved in a liberal singleton.

Hence: the domination of eudaimonia in humanity can best be achieved in a liberal singleton. 
Moreover: Since humanity is becoming increasingly cognitevely+morally enhanced, a liberal singleton is becoming increasingly realistic.

Hence: $(\mathrm{C}+\mathrm{M}) \mathrm{E}$ is becoming increasingly realistic, as is the domination of eudaimonia in humanity.

On the other hand, the following has also been argued: taking into consideration the augmentation of the power of new technologies, it is questionable whether humanity's path to eudaimonia dominated governance in a singleton will ever be achieved. Our future is one in which the stakes are justice (if we attain a eudaimonic singleton) and life (if we do not inflict ultimate harm upon ourselves). In light of the rapid development of new technologies, we cannot have one without the other. The longer we fail to realize a eudaimonic singleton, the higher the likelihood of ultimate harm is going to be. As a matter of fact, we will have to make a choice between an ethical commonwealth in the form of a eudaimonic singleton $(=[\mathrm{C}+\mathrm{M}] \mathrm{E}$ in a liberal singleton) and ultimate harm. Since $(C+M) E$ is the formula of enhancement that has moral enhancement as its objective, the choice will be between moral enhancement and some form and degree of ultimate harm.

\section{References}

Bostrom N. 2006. "What is a Singleton?" Linguistic and Philosophical Investigations 5 (2): 48-54.

Bostrom N. and Savulescu J. 2009. "Introduction - Human Enhancement Ethics: The State of the Debate". In Bostrom N and Savulescu J (eds). Human Enhancement. Oxford: Oxford University Press.

Bostrom N. and Roache R. 2011. "Smart Policy: Cognitive Enhancement and the Public Interest". In Savulescu, J., Ter Meulen, R. and Kahane, G (eds.). Enhancing Human Capacities. Oxford: Wiley-Blackwell.

Doyle, M. 1983. "Kant, Liberal Legacies, and Foreign Affairs (parts I ands II)". Philosophy and Public Affairs 12 (3):| 205-35 (I) and 12-4: 323-53 (II).

Hanson, R. 2009. "Enhancing Our Truth Orientation". In Bostrom N and Savulescu J (eds). Human Enhancement. Oxford: Oxford University Press.

Jones, G. 2008. "Are Smarter Groups More Cooperative? Evidence from Prisoner's Dilemma Experiments, 1959-2003“. Journal of Economic Behavior and Organization 68 (3-4): 489-97.

Kant, I. 1788. Die Kritik der praktischen Philosophie (erste Ausgabe).

Kant, I. 1793. Religion innerhalb der Grenzen der bloßen Vernunft (erste Ausgabe).

Persson I. and Savulescu J. 2008. "The Perils of Cognitive Enhancement and the Urgent Imperative to Enhance the Moral Character of Humanity". Journal of Applied Philosophy 25 (3).

Persson, I. and Savulescu, J. 2011a. "Unfit for the Future? Human Nature, Scientific Progress, and the Need for Moral Enhancement". In Savulescu, J., Ter Meulen, R. and Kahane, G (eds.). Enhancing Human Capacities. Oxford: Wiley-Blackwell. 
Persson I. and Savulescu. 2011b. "The Turn for Ultimate Harm: A Reply to Fenton". Journal of Medical Ethics. Online first publication of 22 February, 2011.

Persson I. and Savulescu. 2013. "Should Moral Bioenhancement be Compulsory? Reply to Vojin Rakic". Journal od Medical Ethics. Published Online First: 22 March 2013 doi:10.1136/medethics-2013-101423

Rakić, V, 2010a. A Theory of the Normartive Will. Beograde: Faculty of Economics and Poolitical Science and the Center for Ethics, Law and Applied Philosophy.

Rakić, V. 2010b. "The Political Hypnosis of the Owl of Minerva". Godišnjak Fakulteta političkih nauka 4.3: 49-76.

Rakić, V. 2012. „From Cognitive to Moral Enhancement: A Possible Reconciliation of Religious Outlooks and the Biotechnological Creation of a Better Human". Journal for the Study of Religions and Ideologies 11(31): 113-128

Rakić, V. 2013a. "Voluntary moral enhancement and the survival-at-any-cost bias". 2013. Journal od Medical Ethics. Published Online First: 14 February 2013. DOI:10.1136/medethics-2012-100700

Rakić, V. 2013b. „Kant's Semantics of World (State) Making“. In: Semantics of Statebulding: Language, Meanings and Sovereignty, eds Nicolas Lemay-Hebert, Nicholas Greenwood Onuf, Vojin Rakić and Petar Bojanić. London: Routledge.

Tannsjo, T. 2009. "Medical Enhancement and the Ethos of Elite Sport". In Bostrom $\mathrm{N}$ and Savulescu J (eds). Human Enhancement. Oxford: Oxford University Press. 